\title{
ENSAIO SOBRE CENTRALIZAÇÃO, DESCENTRALIZAÇÃO E CONTROLE SOCIAL
}

Resumo: Este artigo pretende produzir reflexões acerca da ênfase dada pelo discurso caracterizado como municipalista, sob a ótica do poder executivo municipal, privilegiando a descentralização financeira e em nenhum momento apresentando qualquer preocupação com o favorecimento $e$ ampliação dos espaços de participação popular e a partir deles a emergência de experiências inovadoras em programas sociais e nos próprios modelos de gestão. Para tal apresenta-se alguns subsídios sobre as possibilidades dos movimentos de centralização e descentralização a partir do movimento da reforma do Estado, abordando as dificuldades a partir de um cenário brasileiro marcado por heterogeneidades e desigualdades sociais políticas e econômicas, pautado fundamentalmente nas considerações de Souza e Carvalho (1997) e Arretche (1997). Em seguida, destaca-se alguns aspectos conceituais básicos sobre a descentralização e desconcentração, com
Lina Glaucia Dantas ELIAS ${ }^{1}$

Universidade Federal do Pará-UFPA lina@ufpa.br

Vânia Katia Dantas Elias DAVID ${ }^{2}$ Universidade Federal do Pará-UFPA katiadantaselias@gmail.com base nas análises de Lobo (1990) e Casassus (1995). Para então, discorrer-se pela análise do controle social, como experiência de participação social tomando como base os Conselhos Municipais, partindo das reflexões de Spozati e Lobo (1992). Por fim, este estudo pretende realizar algumas reflexões iniciais sobre a descentralização e controle social como desejo e possibilidade de democratização e participação dos setores populares na gestão pública.

Palvras-Chaves: Descentralização. Centralização. Municipalização. Controle Social

\footnotetext{
${ }^{1}$ Mestra em educação - Políticas Públicas Educacionais -, Pedagoga, Professora da UFPA - Universidade Federal do Pará, Campus Abaetetuba -, Líder do GEPESEED - Grupo de Pesquisa Sociedade, Estado e Educação, com ênfase nos governos municipais.

${ }^{2}$ Especialista em Metodologia da Pesquisa e Gestão Pública, Assistente Social e Economista, Consultora na Elaboração de Projetos para Modernização da Gestão Pública da SEAD - Secretaria de Administração do Estado do Pará - e integrante do GEPESEED - Grupo de Pesquisa Sociedade, Estado e Educação, com ênfase nos governos municipais .
} 
Abstract: This article aims to produce reflections on the emphasis given by speech characterized as municipalist, from the perspective of municipal executive, focusing on financial decentralization and at no time having any concerns about favoritism and increase opportunities for public participation and from them the emergence of innovative experiences in social programs and in their own management models. To this, brings some subsidies on the possibilities of centralization and decentralization movements from the movement of reform of the state, focusing the difficulties from a Brazilian context marked by heterogeneities and social inequalities and economic policies, guided primarily on considerations of Souza and Carvalho
(1997) and Arretche (1997). Then we highlight some basic conceptual aspects of decentralization and deconcentration, based on the analysis of Lobo (1990) and Casassus (1995). By then, talks by the analysis of social control, and social participation experience building on municipal councils, leaving reflections of Spozati and Lobo (1992). This study intend to conduct some initial reflections on decentralization and social control as desire and possibility of democratization and participation of ordinary people in public management.

Key Words: descentralization. centralization. mucipalization. social control. 


\section{Introdução}

Conforme Vedana (2002), a autonomia ideal será realizada somente quando forem satisfeitas as aspirações do movimento municipalista pelas entidades organizadas e o Congresso Nacional discutir efetivamente uma melhor descentralização das receitas, com uma regulamentação da melhor distribuição dos encargos que possa garantir autonomia do poder local, por meio do equilíbrio entre receitas auferidas e encargos administrativos e investimentos necessários para o cumprimento das suas finalidades administrativas junto à população. Com esta concepção o movimento de mobilização dos Prefeitos Municipais e das entidades de representação dos municípios brasileiros têm buscado inserir as suas reivindicações no cenário nacional e nele conquistarem o devido espaço.

A ênfase dada pelo discurso caracterizado como municipalista, sob a ótica do poder executivo municipal, privilegia a descentralização financeira e em nenhum momento apresenta qualquer preocupação com o favorecimento e ampliação dos espaços de participação popular e a partir deles a emergência de experiências inovadoras em programas sociais e nos próprios modelos de gestão.

Na verdade esta é uma concepção evidente da defesa de um projeto político que, como veremos mais adiante, se contrapõe ao conceito de descentralização que queremos discutir. Não nos proporemos aqui a incorrer pelo aprofundamento da análise do discurso do municipalismo, mas tão somente para iniciar a discussão ilustrando de acordo com Souza \& Carvalho (1997) algumas reflexões sobre os limites e as possibilidades dos processos de descentralização, da participação e do controle social em espaços com escassa infraestrutura cívica e cidadã; em espaços onde o emprego público é uma forma de compensar a ausência de ocupações nos setores econômicos; em como considerar o processo de descentralização, a participação da sociedade e a constituição das organizações sociais, em países com grandes heterogeneidades regionais e sociais. Que descentralização nós queremos? 


\section{A reforma do Estado e a descentralização.}

Os processos de centralização e descentralização nos países em desenvolvimento como o Brasil devem ser compreendidos a partir de uma referência às mudanças no atual modelo de produção mundial, qual seja, a análise do modo de inserção subordinada destes países na economia internacional.

Na realidade, é esse modo de inserção subordinada do país na economia internacional que vem aprofundando a adoção de uma política neoliberal, em que se acentua a ênfase na desregulamentação dos mercados, na abertura comercial e financeira, na privatização do setor público e na redução do Estado, atingindo-se particularmente toda a área de investimento social, sob o pretexto do equilíbrio das contas públicas. (ROSAR, 2003 ,p.65)

A subordinação dos países periféricos aos países centrais foi acentuada pelos empréstimos externos, que no caso brasileiro iniciaram-se no Governo Vargas, consolidandose durante o período militar com um movimento tendente à centralização econômica e política. Só para ilustrar, durante a ditadura militar, na década de 70, os governos militares brasileiros tomaram vultosos empréstimos junto aos bancos estrangeiros a juros flutuantes. Ou seja, os bancos poderiam aumentar o quanto quisessem as taxas de juros a serem pagas. Nos anos 90, mais um ciclo de endividamento externo foi tomado para financiar o Plano Real.

Neste contexto, aprofunda-se o ideário das políticas neoliberais com a criação de diversas instâncias governamentais de âmbito internacional, tais como o FMI e o Banco Mundial os quais induzem e orientam as políticas econômicas nacionais. Trata-se do que Ianni (1992,p.133) denominou de "colonialismo de mercado", para caracterizar a subordinação de povos e governos às forças de mercado que acentuam as desigualdades sociais entre países e no seu interior.

O movimento globalizante obedece aos desideratos dos grandes grupos industriais e dos detentores dos vastos recursos financeiros. Nas formas que atualmente se manifesta, o capital exige submissão à ordem econômica existente. Assim, novas exigências são postas e 
a necessidade de adequação das agendas nacionais a esta nova ordem mundial é premente, através da consolidação da Reforma do Estado.

No Brasil, com a instituição do Plano Real, durante o Governo Itamar Franco, introduz-se o elemento que dá sustentação e justificação às reformas. Contudo, foi no Governo de Fernando Henrique Cardoso que a chamada Reforma do Estado adquiriu um formato definitivo e conceitual.

De acordo com Souza \& Carvalho (1997, p.196) o modelo de reforma foi idealizado pelo Ministério da Administração Federal e Reforma do Estado-MARE, fundamentalmente em decorrência do ajuste fiscal e centrava-se na busca da melhoria da ação burocrática, na separação das atividades de regulação das de execução e na modernização fiscal dos entes subnacionais.

$\mathrm{Na}$ análise das autoras a reforma do Estado aconteceu em duas gerações, sendo que a primeira delas objetivava a racionalização dos recursos fiscais, através da abertura dos mercados, desregulamentação e privatizações. Afetando mais significativamente as esferas locais e as políticas sociais, a segunda geração de reformas objetivava: a eficiência dos serviços públicos, a efetividade, a democratização com o envolvimento da comunidade nas decisões relativas às ações públicas e a descentralização para as esferas subnacionais das responsabilidades de provisão de infraestrutura e dos serviços sociais. Inicia-se assim o debate a respeito do novo papel a ser assumido pelo Estado através de sua reforma voltada

“[....] fundamentalmente, para o fortalecimento das funções de regulação e coordenação do Estado, principalmente no nível federal, assim como para uma reconstrução da administração pública em bases "modernas" e "racionais", superando o modelo burocrático e assumindo um caráter gerencial, orientado pelos valores da eficácia e da qualidade e para o controle dos resultados. Nesse sentido, a ação direta do Estado e a burocracia pública deveriam ficar limitadas àquelas atividades que envolvem diretamente o poder do Estado( cobrança de impostos, polícia e previdência básica, por exemplo), buscando-se uma melhoria da atuação e uma valorização do servidor no núcleo estratégico e nas denominadas funções exclusivas do Estado". (SOUZA \& CARVALHO, p. 198). 
Assim, o Governo Federal vai transferindo as ações na área de habitação, saúde, saneamento, educação e assistência social para a responsabilidade dos estados e municípios, como parte da concepção da lógica da delimitação do tamanho do Estado, da redefinição do seu papel regulador, da recuperação das capacidades financeiras e administrativas de implementação das decisões governamentais e do aumento da governabilidade no sentido de tornar efetivas essas decisões.

Neste contexto, é que se salienta a argumentação fundamental da análise de Souza \& Carvalho (1997) de que a reforma do Estado ao deixar de considerar a sua implementação em países caracterizados por extremas heterogeneidades e desigualdades termina por não assegurar que estados e municípios com baixo grau de desenvolvimento econômico e institucional ampliem de forma eficiente suas responsabilidades sociais. Os autores indagam sobre a pertinência e viabilidade de transpor para o contexto desses países modelos, mecanismos e instrumentos de gestão originários da experiência de outras sociedades bem diferenciadas e mais afluentes. Assim analisam:

Nessa perspectiva, ao analisar a aplicabilidade de paradigmas e experiências oriundas de outros países, é preciso não esquecer que, naquelas sociedades, os arranjos institucionais para atender às imposições da reestruturação produtiva e ao aumento da competição capitalista em escala mundial ocorrem em torno da disputa pela preservação de direitos sociais efetivamente usufruídos e de embates contra mecanismos de opressão de identidades sociais, étnicas e culturais. Já no Brasil, o histórico alijamento de grandes parcelas da população do acesso a um mínimo de garantias sociais transforma a luta por direitos em pressão por políticas públicas redistributivas e conjuga o desafio do ajuste à nova ordem ao combate à exclusão social, acentuada mais recentemente pelos custos desse próprio ajuste. (SOUZA \& CARVALHO,1997,p.200).

Neste contexto, as autoras fazem uma análise da descentralização das políticas sociais a partir das desigualdades existentes no Brasil refletidas nas diferenças nas condições financeiras, políticas e administrativas das entidades subnacionais e na sua capacidade de resposta às necessidades e demandas da população. Significa que o processo de descentralização por ser uma das dimensões basilares da reforma deve ser pensado a partir de sua implementação, levando-se em conta as dificuldades financeiras, institucionais, 
técnicas e políticas dos municípios para assumirem esse novo papel. A esse respeito Arretche (1997) comenta da necessidade de se definir estratégias e mecanismos os quais incentivem a adesão do nível de governo a que se dirigem.

Nesta discussão acrescenta-se ainda mais o arrasador impacto da globalização sobre o Estado-Nação, a medida que priva de significado as atitudes e comportamentos específicos de uma nação pela falta de capacidade de decisões de investimento seja social ou econômico a partir de critérios decorrentes de um planejamento governamental soberano. E nesta perspectiva situar a complexa participação do governo federal e dos recursos públicos nacionais para estados e municípios, devido às atuais políticas financeiras e fiscais de cumprimento do superávit primário, que colocam os entes federados em constante rota de colisão.

\section{Alguns elementos conceituais básicos.}

Lobo (1990) buscar esclarecer algumas incompreensões conceituais sobre o termo descentralização, que comumente se confunde com desconcentração, na qual os discursos oficiais acabam por utilizar os termos como sinônimos.

Repetindo, a descentralização envolve necessariamente alterações nos núcleos de poder, que levam a uma maior distribuição do poder decisório até então centralizado em poucas mãos. Esta a razão por que fica mais cômodo e tranquilo para o governo assentado em bases centralistas privilegiar a desconcentração e rotulá-la de descentralização. (LOBO, 1990, p.6).

A autora considera que a desconcentração implica em um processo de mudança que leva em conta uma dispersão físico-territorial das agências governamentais que estavam localizadas centralmente. Já o processo de descentralização pressupõe uma alteração nas estruturas consolidadas e na distribuição do poder.

$\mathrm{Na}$ verdade, confundir os conceitos e aceitar a desconcentração como descentralização implica em encobrir as dificuldades do encaminhamento 
concreto desta última. Isto porque a desconcentração não ameaça tanto as estruturas consolidadas. [...] Em termos concretos, quando se quer transformar um aparato político-institucional consolidado em bases centralizadoras, a partir de um movimento oposto-descentralizador, fatalmente dever-se-á mexer em núcleos de poder bastante fortes. (LOBO, 1990,p.6).

Interessante complementar aqui a contribuição de Casassus (1997), que indica ser a diferença fundamental entre descentralização e desconcentração, pois esta última reflete processos os quais encaminham no sentido de assegurar a eficácia do poder central, um movimento verticalizado de "cima para baixo", que acaba por fortalecer os "coronelismos locais" à medida que reproduzem as práticas das relações tradicionais de centro-periferia. Já a descentralização seria um processo com tendência a assegurar a eficácia do poder local, refletindo um movimento de "baixo para cima", porquanto percebido como um processo de redistribuição de poder.

$\mathrm{Na}$ análise deste autor o conceito deve ter presente, preliminarmente dois aspectos: $\mathrm{o}$ primeiro se refere à repartição entre as esferas do poder público, que termina por constituir os municípios em entidades executoras das políticas geradas no nível superior e o outro diz respeito ao próprio conceito: descentralização de poder ou desconcentração de tarefas? Ato político ou ato administrativo? Se ato político para quem é transferido o poder?

Apesar de algumas experiências inovadoras, em geral o que ainda se percebe é uma desconcentração de tarefas ou a descentralização administrativa, permanecendo inalteradas a estrutura e as relações de poder. Nestes casos, no máximo parcelas de poder decisório mudam de esfera, mas o poder continua concentrado no Executivo, seja Federal, Estadual ou Municipal, resquício de uma visão patrimonialista da coisa pública, como pertencente à vontade do governante.

O processo de descentralização pode ser analisado do ponto de vista técnico, político, econômico e administrativo, no entanto é na questão do poder, na sociedade, que se encontra sua base. Tanto os processos de centralização quanto de descentralização refletem a forma de organização da sociedade, da distribuição e redistribuição do poder e de como se articulam processos de coesão social e de como acontece o fluxo de poder na sociedade civil. Outro 
termo que tem causado confusão conceitual com o processo de descentralização refere-se à municipalização, este último entendido como a transferência de serviços executados pelos governos centrais aos municípios.

O processo de descentralização é aqui entendido como contendo tanto os elementos da desconcentração quanto os da municipalizaçãoe que encarado dentro de seus reais limites constitui-se em um importante instrumento para promoção de alterações políticoinstitucionais capazes de fazer avançar a democratização do Estado e possibilitar o controle social da população organizada sobre a ação do poder público.

A descentralização deve ser compreendida a partir das contradições do Estado, suas possibilidades de penetrar sua instância objetiva, o nível de gestão do sistema, assim podendo democratizá-lo. A descentralização e o fortalecimento da autonomia municipal poderão favorecer o crescimento da força política da classe trabalhadora se representarem uma oportunidade para o fortalecimento do poder popular.

Feitos estes esclarecimentos conceituais iniciais, avança-se na caracterização da descentralização quando Lobo (1990) enumera alguns princípios que devem servir como norteadores da descentralização: flexibilidade, gradualismo, transparência no processo decisório e criação de mecanismos de controle social. A flexibilidade da ação descentralizadora procura levar em consideração as desigualdades inter-regionais, as diferenças econômico-financeiras, políticas, técnico-administrativas e sociais estabelecidas internamente em cada governo subnacional. Assim ela se expressa:

[...]A flexibilidade da ação descentralizada implica em levar em consideração as diferenças econômico-financeiras, políticas, técnicoadministrativas e sociais, que fazem com que os governos estaduais e municipais tebham distintas capacidades de respostas às demandas que se lhes apresentam. Vale lembrar que o tratamento assimétrico não se resume às diferenças inter-regionais. As desigualdades intraregionais são tão ou mais importantes que as primeiras[...] (LOBO, 1992,p.8)

Com relação a este princípio, Souza \& Carvalho (1996) vão mais além e analisam que a descentralização não ocorre em um vazio político, institucional e econômico enfatizando 
seus limites em países marcados por heterogeneidades e desigualdades como o Brasil. Continuam refletindo que mesmo nas áreas mais desenvolvidas do país a heterogeneidade existente torna muitas vezes problemática a capacidade de atuação da esfera local.

[...]A parcela de municípios que dispõem efetivamente de condições financeiras, institucionais, políticas e técnico-administrativas para assumir esse papel, inovando, ampliando a eficácia, a participação e a democratização das políticas públicas, é relativamente pequena. $\mathrm{Na}$ maioria dos casos o que se denota nas regiões e áreas menos desenvolvidas, são municípios de reduzido porte, com economia de base agrícola pouco diversificada, estagnadas ou em crise, por isso mesmo, desprovidos de condições mínimas de sustentação e necessitando da solidariedade dos governos estaduais e federal.[...] (Souza \& Carvalho, 1997,p.203)

Ainda de acordo com a autora, em que pese todos os constrangimentos financeiros dos municípios, eles também estão ampliando suas ações e responsabilidades na área social. Os gastos na educação e saúde têm crescido e diversas experiências inovadoras têm sido amplamente divulgadas. Ressalva, porém, que a maior parte dessas iniciativas se localizam nas áreas mais desenvolvidas do país, no que conclui que a descentralização das políticas sociais avança de forma diferenciada e descontínua com características e efeitos tão heterogêneos como o próprio país e não necessariamente virtuosos.

O processo de descentralização coloca em cheque a concepção de paradigmas únicos e universais para o setor público, pois talvez seja mais sensato reconhecer que a provisão dos serviços e o futuro da administração pública assumirão caminhos plurais e diversificados. Apesar dos processos de redemocratização e as disposições da Constituição de 1998 terem proporcionado o fortalecimento do poder político e dos recursos financeiros dos governos subnacionais, favorecendo especialmente os estados e suas capitais, em um país com vasta dimensão territorial, marcado por profundas desigualdades inter e intra-regionais e sociais, os efeitos da descentralização tendem a variar substancialmente. (SOUZA \& CARVALHO,1997).

Estabelecidas estas reflexões, volta-se ao segundo princípio definido por Lobo (1990), o gradualismo que trata da impossibilidade de descentralizar de forma abrupta e 
repentina, pois dadas as desigualdades acima referidas à descentralização só será eficaz se for adequada a um continuum de tempo e espaço. Neste sentido, a descentralização só terá eficácia se ensejar para que as transformações na direção de novos arranjos políticoinstitucionais aconteçam progressivamente a partir de capacidades reconhecidas e aceitas que assegurem a consolidação do seu próprio movimento.

A transparência no processo decisório é o terceiro princípio e pressupõe que na medida em que visa a redirecionar núcleos de poder, até então localizados no nível central obtenha a adesão consciente e compromissada dos sujeitos envolvidos, a participação direta nas etapas decisórias, as quais oportunizam mudanças que alteram as regras do jogo.

A criação de mecanismos de controle social é o quarto princípio, no qual a participação da sociedade organizada cria mecanismos político-institucionais de articulação, canais orgânicos de comunicação constante, com diversas experiências já ocorrendo através do planejamento participativo, dos conselhos, coordenações, nas áreas de educação, saúde, meio ambiente e outras. Assumindo o controle social como premissa básica no processo de descentralização, pode-se afirmar que não há porque descentralizar se quiser manter-se intacto o poder absoluto do Estado, mesmo no nível regional ou local, já que estes podem ser tão centralizadores quanto o governo federal.

A esse respeito Arretche (1997) faz uma análise do debate travado nos anos 80, na perspectiva de desmistificar o consenso criado em torno da descentralização enquanto processo que necessariamente encaminha para a concretização de ideais democráticos e que formas de gestão centralizadoras estão vinculadas a práticas não democráticas de decisão. A autora refuta estas argumentações ao afirmar que o estabelecimento dos ideais democráticos, independentemente do seu conteúdo ideológico, dependem muito mais da natureza das instituições que em cada nível de governo devem encaminhar as decisões, do que necessariamente da escala ou nível de governo encarregado da gestão das políticas.

Pode parecer ingênuo afirmar ( pois na verdade, uma concepção que associava gestão do nível central de governo à ausência de democracia esteve presente no debate), mas o simples fato de que determinadas questões ou políticas sejam geridas (e/ou tenha seus mecanismos decisórios processados) pelo nível central não é 
indicador de uma gestão menos (ou mais) democrática. Isto não significa que a descentralização de um conjunto significativo de decisões políticas não possa ser um elemento de radicalização e aprofundamento da democracia nas circunstâncias atuais. Mais que isso, faz sentido supor que instituições de âmbito local, dotadas de efetivo poder, possam representar um incentivo à participação política, dado que podem possibilitar formas mais efetivas de controle sobre a agenda e sobre as ações de governo. No entanto, não é suficiente que se reforme apenas a escala ou âmbito da esfera responsável pela decisão a ser tomada. É necessário que se construam instituições cuja natureza e cujas formas específicas de funcionamento sejam compatíveis com os princípios democráticos que norteiam os resultados que se espera produzir. ( ARRETCHE, 1997)

O autor considera que é no interior das instituições políticas, no processo histórico de sua formação, que as elites de diferentes instâncias estão ou não integradas que se explicam a natureza das reformas descentralizadoras. Advoga ainda a tese de que o processo de descentralização não esvazia as funções do nível central de governo à medida que um resultado positivo da descentralização está condicionado à redefinição do papel estratégico do governo a partir de um novo pacto federativo. ${ }^{3}$

\section{Controle Social}

Historicamente os processos de centralização administrativa e financeira no Brasil remontam ao período do colonial e mais especificamente durante o regime autoritário de 1964, no qual a concentração de recursos fiscais e a formulação de políticas nacionais na União foi sem precedentes.

Na década de 80 vivencia-se no Brasil o período de redemocratização e amplia-se a participação popular. Através dos movimentos sociais e da luta sindical, surgem novas elites regionais, governadores, prefeitos e parlamentares consolidando um novo arranjo político, reduzindo o poder de comando antes exercido inteiramente pelo Governo Central.

\footnotetext{
${ }^{3}$ Para uma análise sobre o pacto federativo, ver, Kugelmas \& Sola (1999). 
Neste contexto, fortaleceram-se no país os debates entre descentralização e democratização, com a descentralização administrativa e de poder político sendo consideradas condições necessárias para o processo de democratização do governo. Inverter a tendência centralizadora do período autoritário no que se refere às políticas sociais passou a ser um objetivo comum a todos os atores, quer por motivações ideológicas, quer por razões de eficácia técnica.

$\mathrm{Na}$ vivência de intensos processos de luta e conquistas sociais, alguns consensos foram se consolidando, como o reconhecimento da importância do papel estratégico do controle social sobre o Estado a partir da sociedade civil. Apesar das mais diversas tendências de práticas de participação social, das quais o controle social é uma delas, para os fins deste debate reportar-se-á a discutir as experiências de controle social nas quais há uma co-gestão entre Estado e sociedade civil

Sposati \& Lobo (1992) encaminham a discussão sobre o controle social no sentido de se criar uma nova cultura política/democrática que ao democratizar as decisões traga o sentido de alteridade, ou seja, a presença do outro. O uso do conceito originário da psicologia indica que um e outro são sujeitos, portanto protagonistas de decisões e ações. A alteridade assim compreendida marca a presença de um sujeito que se contrapõe, que tem força e presença para pressionar e ter protagonismo, que pela sua posição histórica e social, representa um polo com capacidade de se contrapor àqueles que detém o poder institucional.

As experiências das autoras na área de saúde evidenciam que a representação popular em conselhos é sem dúvida, um avanço, mas um avanço face ao autoritarismo do passado. No entanto, é necessário estender o poder da representação popular para a construção e gestão das políticas sociais e neste sentido a questão que se coloca não é se o controle social melhora os serviços públicos, mas em como se dá esse controle ou em quanto ele se tem tornado um efetivo exercício democrático. Ou talvez se deva perguntar qual o grau de apropriação popular das políticas públicas a partir do controle social.

Sposati \& Lobo (1992) esclarecem que no princípio dos anos 80, marcava a discussão da clara autonomia popular dos conselhos de saúde frente à organização estatal, o que foi conquistado com a definição das representações dos movimentos como interlocutores das 
necessidades populares. A forma de regularização e de normalização da presença popular na gestão de saúde indicou o caminho tripartite, envolvendo os trabalhadores de saúde, os dirigentes e a representação popular. A esse respeito os autores comentam:

Todavia, a indagação é se esta legitimidade deve ser legalizada e institucionalizada e como trabalhar as questões decorrentes de uma possível institucionalização.Uma questão se refere à relação instituido-instituinte. O movimento social não deve se transformar em uma "personalidade jurídica", sob pena de reduzir sua particularidade e sua capacidade de interlocução a mais uma das “entidades ou organizações sociais". É próprio do movimento a sua capacidade instituinte. Todavia o conselho de saúde que não é, nem pode ser, o movimento, ainda que deva manter com ele uma relação orgânica, necessita ser intitucionalizado a fim de constituir uma "regularidade" no fluxo decisório da instituição.Em outras palavras, necessita constituir um sujeito coletivo regular ou contínuo, com delegação de autoridade para poder influir na gestão e produção das políticas de saúde. O funcionário, que, às vezes, era um "interlocutor clandestino", virou "interlocutor oficial". Podemos dizer que o conselho de saúde, que era oposição, virou situação. $O$ grande risco nesta nova institucionalidade é o de se transformar em mais uma burocracia"( SPOSATI \& LOBO, 1992)

Estas reflexões sobre a institucionalidade das organizações indicam que não basta criar conselhos, comissões, comitês. É necessário estabelecer a forma como estes influenciarão as decisões institucionais. Neste sentido respondem Sposati e Lobo (1992) que para o controle social ser exercido de fato necessita de regularidades organizacionais. São estas que irão ensejar a questão do grau de democratização interno das organizações o qual demarca o fluxo do processo decisório e o grau de influência de cada instância ou unidade de organização na gestão institucional. É necessário ter claro o canal, ou canais, pelos quais ocorrem a interferência na dinâmica da instituição. Os espaços de controle social ao provocarem a democratização institucional necessitam que se torne claro o campo da sua organização interna, em que todos os assuntos passam pelo espaço de alteridade, fazendo-se acontecer o que foi decidido. 
É possível que tenha ficado mais claro ao movimento discutir e cobrar as ações quando o Estado estava sob governos autoritários, que demarcavam com quem estava o poder, em geral centralizado, do que nos estilos de gestão soft, ou pretensamente democráticos, que, ao diluir a autoridade, por entendê-la autoritária, constróem uma fluidez que não demarca os territórios de decisão. Esta é a falsa descentralização, que desconcentra ações, mas não poderes.A construção democrática é mais palco de uma relação de conflito do que de consenso, o que não é fácil nem de se admitir nem de se enfrentar. (SPOSATI \& LOBO, 1992)

Um outro aspecto levantado pelas autoras trata da construção democrática pressupondo uma relação de complexidade, de conflitos e negociações que passam pelo convívio de múltiplos sujeitos e interlocutores. Neste contexto, é importante destacar as reflexões acerca do interculturalismo refletidas no texto de Lopes (2005) quando diz:

Em suma, podemos destacar que dentre os elementos estruturadores da interculturalidade, estão: o reconhecimento do outro como interlocutor em igualdade de condições, o reconhecimento de uma outra cultura como parte da estrutura vivencial que se possui, a valorização da diversidade cultural de um povo, a superação das desconfianças e de estereótipos, aprendizagem coletiva, a efetiva comunicaçao entre os grupos e a promoção da capacidade de trabalho em conjunto. (LOPES,p.16)

Neste sentido, a autora demarca alguns princípios básicos sobre o controle social:

1. a suposição de um padrão de representatividade na construção, operação e gestão das políticas sociais, com capacidade de se contrapor, influir ou assumir seu poder de mudança;

2. a possibilidade de ruptura com o caráter privatista, de favorecimentos, exercitando a construção popular da democracia, que é uma exigência da sociedade brasileira, tradicionalmente autoritária, elitista, paternalista e clientelista no seu estilo de fazer política;

3. que a relação social fundadora dos espaços de controle social seja capaz de estabelecer regras que definam espaços de influência, rompendo a continuidade burocrática de reuniões sem compromisso com a alteridade; 
4. a necessidade de sua institucionalização e de tornar públicas as ações e decisões para os representados e para a instituição;

5. que o controle social deve incidir não somente sobre a equidade dos resultados, mas também sobre a igualdade do acesso, ou seja, ampliar o controle social para além de mecanismo de regulação para os serviços existentes, mas também para a perspectiva do que ainda deve ser feito para garantia do direito a todos.

\section{Considerações finais: pode-se desejar ser outra coisa?}

Conforme procurou-se demonstrar nas páginas anteriores, os debates sobre centralização e descentralização envolvem uma análise da transformação do papel e das ações do Estado. O Estado brasileiro e, por conseguinte a gestão pública, têm uma história autoritária, privatista, a serviço de um modelo hegemônico planejado para ser em sua ação, indiferente a seu entorno.

Difunde-se como senso comum a inevitabilidade dos novos modos de regulação social dos padrões de relação entre Estado, sociedade e mercado. No bojo da Reforma do Estado, o movimento dos governos neoliberais desobrigam-se de encargos sociais gerando uma transferência de responsabilidades para as instâncias locais. Neste contexto, os processos de descentralização acabam por representar um esforço de "economia de recursos" que produzem o encolhimento das políticas sociais, reduzindo-as às políticas compensatórias.

A história do país registra ciclos de concentração de poder e de desconcentração de tarefas para as instâncias locais. A prática tem sido a desconcentração de tarefas ou a descentralização administrativa, mas não a política, permanecendo inalteradas as estruturas e as relações de poder. O desejável não é a transferência do poder de uma esfera de comando para outra, mas a democratização do exercício do poder, através da participação das organizações sociais como centro das estratégias de mudança social.

Democratização, descentralização e o fortalecimento municipal são reivindicações populares, mas é preciso garantir o controle do processo pela sociedade civil, sendo necessário construir e fortalecer o poder popular, considerar que a força política da sociedade reside fundamentalmente em sua capacidade de organização e mobilização e também de sua capacidade em formular propostas que apresentadas ao conjunto da sociedade gerem a adesão 
e o apoio político necessário para legitimá-las e institucionalizá-las. No entanto, resistências vêm sendo esboçadas às novas configurações sociais impostas pelo atual modelo de produção mundial, buscando mudanças pela ressignificação das medidas impostas e na construção de um novo espaço público.

Nesta perspectiva, diferentes práticas e experiências de gestão democrática e participação social têm se mostrado como reações a este modelo hegemônico, fundamentalmente naquelas em que há uma co-gestão entre governo e sociedade civil tais como os orçamentos participativos, os Conselhos Municipais, Conferências, dentre outros. A prática de controle social através dos Conselhos Municipais aqui destacada nos mostra que o processo de democratização da sociedade não é uma das tarefas mais fáceis, mas que tais práticas se apresentam como possibilidade de acabar com as bases de uma cultura patrimonialista, autoritária e clientelista, enraizada na estrutura estatal e até mesmo no poder de organização dos próprios movimentos sociais. Portanto, a democratização do acesso aos serviços sociais básicos de qualidade será assegurada através da luta organizada dos setores populares e de sua participação efetiva nos órgãos e instâncias de gestão e controle social das políticas públicas. Mesmo fora dos objetivos deste trabalho, é importante ressaltar que algumas ações e práticas participativas, apesar de não estarem voltadas para a co-gestão e cuja incidência não se dá pelos canais institucionalizados, acabam por alterar as agendas públicas, tais como, Fórum em defesa de Vida e pela Violência, Pastoral da Criança e outros.

Tais experiências se colocam como alternativas capazes de construir novos valores e são um movimento contra hegemônico que caminhe na construção do poder popular, contribuindo para uma cultura democrática e participativa, ensejando a capacidade de implementar políticas inovadoras quanto à melhoria das condições de vida de toda a população e a democratização dos processos de gestão. 


\section{Referências Bibliográficas.}

ARRETCHE, Marta. A Miragem da pós-modernidade: democracia e políticas sociais no contexto da globalização. In: GERSCHMAN, Silvia \& VIANA, Maria Lucia W. (Org) 0 Mito da descentralização como indutor de maior democratização e eficiência nas políticas públicas. Rio de Janeiro: Fiocruz, 1997. p.127-51.

CASASSUS, Juan. Tarefas da educação. Campinas,SP: Autores Associados, 1995.p.67-89.

KUGELMAS, Eduardo \& SOLAS, Lourdes. Recentralização, Descentralização, dinâmica do Regime Federativo no Brasil nos anos 90. Tempo Social, Revista de Sociologia da USP, v.11,n.2, out.1999.

LOBO, Thereza. Descentralização: conceitos, princípios, prática governamental. São Paulo: Cortez, Cadernos de Pesquisa. Fundação Carlos Chagas, n.74, ago.1990. p.5-10.

ROSAR, Maria de Fátima Félix. Articulações entre a Globalização e a descentralização: impactos na educação brasileira. In: LOMBARDI, José Claudinei (org.) Globalização, pósmodernidade e educação: história, filosofia e temas transversais. 2 ed.ver.ampl. Campinas,SP:Autores Associados, 2003.

SOUZA, Celina \& CARVALHO, Inaiá M. M. de. Reforma do Estado, Descentralização e desigualdades. Lua Nova; Revista de Cultura e Política, n.48, 1997. p.187-211.

SPOSATI, Aldaíza \& LOBO, Elza. Controle Social e Políticas de Saúde. Rio de Janeiro, Cadernos Saúde Pública, v.8, n.4, out/dez, 1992.

VEDANA, Celso. Federalismo: Autonomia Tributária Formal dos Municípios. Florianópolis:Habitus,2002. 